\title{
AVALIAÇÃO FÍSICO-QUÍMICA E SENSORIAL DE MANDIOCA PRÉ-PROCESSADA ARMAZENADA SOB CONGELAMENTO
}

\author{
ANA VÂNIA CARVALHO* \\ LARA LIMA SECCADIO** \\ THAÍS CRISTINA LIMA SOUZA** \\ TAYSE FERREIRA FERREIRA ** \\ LAURA FIGUEIREDO ABREU***
}

\begin{abstract}
O objetivo do presente trabalho foi avaliar as modificações físicoquímicas e sensoriais de mandioca pré-processada, durante armazenamento sob congelamento. As raízes de mandioca foram selecionadas, lavadas em água corrente, descascadas e cortadas manualmente, higienizadas, acondicionadas em sacos de polietileno e armazenadas sob congelamento a $-18^{\circ} \mathrm{C}$ durante 150 dias, sendo analisadas nos tempos 0, 7, 15, 30, 60, 90, 120 e 150 dias quanto ao $\mathrm{pH}$, acidez titulável, umidade e análise de aceitação sensorial. O valor médio de umidade encontrado para as raízes de mandioca congeladas durante 150 dias foi de 60,65\%. Para a variável pH das raízes de mandioca não foi verificada diferença significativa durante todo o período. No entanto, observou-se acréscimo significativo da acidez nas raízes a partir dos 90 dias de armazenamento. Com relação à análise sensorial, as médias obtidas para todos os atributos avaliados nos tempos zero e 150 dias mantiveram-se praticamente inalteradas e próximas do conceito "gostei muito". Os resultados sugerem que o congelamento de raízes de mandioca préprocessadas constitui método eficiente para retardar o surgimento de modificações e deteriorações, sendo possível prolongar sua vida útil por até 150 dias.
\end{abstract}

PALAVRAS-CHAVE: Manihot esculenta Crantz; MANDIOCA - PRÉ-PROCESSAMENTO; MANDIOCA CONGELAMENTO; ANÁLISE SENSORIAL.

* Doutora em Tecnologia de Alimentos, Pesquisadora da Embrapa Amazônia Oriental, Belém, PA (e-mail: anavania@cpatu.embrapa.br).

** Graduandas, Engenharia de Alimentos, Universidade Federal do Pará, Belém, PA (e-mail: laraseccadio@ hotmail.com; thais.ufpa@ymail.com; ferreira.tayse@gmail.com).

*** Doutora em Tecnologia de Alimentos, Analista da Embrapa Amazônia Oriental, Belém, PA (e-mail: Iaura@ cpatu.embrapa.br). 


\section{INTRODUÇÃO}

A mandioca (Manihot esculenta Crantz) constitui importante fonte de calorias, as quais estão armazenadas na raiz sob a forma de fécula, que serve como base alimentar para grande parte da população da África, da Ásia e da América Latina (COSTA, CARDOSO e OHAZE, 2003).

O Brasil, um dos maiores produtores de mandioca do mundo, lidera a produção latinoamericana com mais de 26 milhões de toneladas anuais, colocando essa cultura entre as principais explorações agrícolas do País (FAO, 2008).

Amandioca de mesa para uso culinário é comercializada como vegetal fresco ou minimamente processada, refrigerada, congelada, ou na forma pré-cozida, facilitando seu preparo e consumo. $\mathrm{O}$ aproveitamento culinário de raízes de mandioca ocorre em todo o mundo, sendo utilizada na forma cozida, assada, frita ou integrando pratos mais complexos (OLIVEIRA et al., 2005).

A mandioca descascada surgiu no mercado como resposta à demanda por produtos de fácil preparo e maior conveniência. No entanto, a alta perecibilidade das raízes na pós-colheita e a facilidade de contaminação microbiológica constituem obstáculos para a maior utilização desse vegetal na forma minimamente processada (ALVES et al., 2005; BRUNO et al., 2005; COSTA, CARDOSO e OHAZE 2003).

Dois tipos principais de degradação podem ocorrer durante a vida pós-colheita de raízes de mandioca. A deterioração primária implica em alterações fisiológicas no vegetal, causadas pela ação de agentes fisiológicos como a enzima polifenoloxidase, que provoca mudança da coloração interna da polpa. A deterioração secundária, de cunho patológico, decorre do ataque de microrganismos que realizam a fermentação do tecido, provocando seu apodrecimento. Os danos fisiológicos iniciam-se durante as primeiras 24 a 72 horas após a colheita, já os danos microbiológicos ocorrem do quinto ao sétimo dia após a colheita. Tanto os danos primários quanto os secundários estão ligados, principalmente, a impactos mecânicos e injúrias que permitem a entrada do oxigênio (que acelera a atuação das enzimas) e facilitam a entrada dos microorganismos (BEZERRA et al., 2002; BORGESFUKUDA e ROSSETTI, 2002).

Dentre os vários métodos que podem ser empregados para a conservação das raízes de mandioca descascadas, o congelamento mostra-se eficiente por controlar ambos os tipos de deterioração: fisiológica e microbiológica (OLIVEIRA, 2010).

O congelamento consiste num dos métodos mais difundidos e utilizados na preservação de diversos alimentos, devido conservação das suas qualidades. Em geral, quanto menor a temperatura de estocagem, menores serão as velocidades de modificações microbiológicas e bioquímicas (BERK, 2009; FELLOWS, 2000). A temperatura afeta não somente a velocidade de reação das enzimas, mas também sua estabilidade. Quando os produtos são congelados em temperaturas bastante baixas, a atividade enzimática permanece interrompida ou em níveis muito baixos. Porém, sua atuação é recuperada após descongelamento (FENNEMA, 1996). Segundo Jay (2000), a capacidade de reprodução dos microrganismos em alimentos congelados também decresce devido à indisponibilidade de condições adequadas, tais como a presença de nutrientes e água livre. Verificou ainda a ocorrência de morte de certos microrganismos sob temperatura de congelamento em virtude de injúrias, desidratação da célula e outras modificações que ocorrem no tecido celular microbiano durante o processo.

Objetivou-se no presente trabalho avaliar as modificações físico-químicas e sensoriais de mandioca pré-processada e armazenada sob congelamento.

\section{MATERIAL E MÉTODOS}

\subsection{PROCESSAMENTO DA MATÉRIA-PRIMA}

As raízes de mandioca, adquiridas de produtores rurais, estabelecidos na cidade de Santa 
Luzia do Pará (PA) foram selecionadas, descartando-se aquelas que apresentavam injúrias. As raízes foram lavadas em água corrente, descascadas manualmente com o auxílio de facas de aço inoxidável e lavadas novamente. Realizou-se o corte das raízes em pedaços de cerca de $6 \mathrm{~cm}$ de comprimento e a higienização em solução de hipoclorito de sódio a $100 \mathrm{mg} / \mathrm{L}$ durante 10 minutos. As amostras foram enxaguadas em solução de hipoclorito de sódio a $5 \mathrm{mg} / \mathrm{L}$, acondicionadas em sacos de polietileno com capacidade para $1 \mathrm{~kg}$ de raízes e armazenadas sob congelamento a $-18^{\circ} \mathrm{C}$.

\subsection{AVALIAÇÃO FÍSICO-QUÍMICA E SENSORIAL}

As raízes congeladas a $-18^{\circ} \mathrm{C}$ foram armazenadas durante 150 dias, acondicionadas em sacos de polietileno de baixa densidade (PEBD), sendo analisadas nos tempos $0,7,15,30,60,90$, 120 e 150 dias quanto ao $\mathrm{pH}$, acidez titulável, umidade (AOAC, 1997) e sensorialmente (STONE e SIDEK, 1993).

Para a análise sensorial, as amostras foram descongeladas e submetidas à cocção em água fervente com adição de $3 \%$ de sal. Manteve-se o cozimento até que o material apresentasse firmeza inferior a $9 \mathrm{~N}$, determinada com auxílio de penetrômetro (marca EFFEGI, modelo FT 327). Equipe de 30 julgadores não treinados, entre funcionários, visitantes e estagiários da Embrapa Amazônia Oriental efetuou a avaliação dos atributos cor, aroma, sabor e impressão global das amostras, usando-se escala hedônica estruturada de 9 pontos ( 9 = gostei muitíssimo; 1 = desgostei muitíssimo) conforme Stone e Sidel, 1993. As amostras foram apresentadas aos potenciais consumidores em pratos plásticos descartáveis, juntamente com as fichas de avaliação.

\section{RESULTADOS E DISCUSSÃO}

\subsection{AVALIAÇÃO FÍSICO-QUÍMICA}

Os dados obtidos para a umidade, acidez titulável e pH da mandioca pré-processada, armazenada durante 150 dias sob congelamento, são apresentados na Tabela 1.

O valor médio de umidade verificado para as raízes de mandioca congeladas e armazenadas durante 150 dias foi de 60,65\%. Alves et al. (2005) encontraram umidade média de 57\% para mandiocas in natura, branqueadas e armazenadas sob refrigeração a $5^{\circ} \mathrm{C}$ por 28 dias. Já Ceni et al. (2009), estudando a composição nutricional de várias cultivares de mandioca descascadas, cortadas, armazenadas em embalagens plásticas e submetidas a congelamento a $-8^{\circ} \mathrm{C}$ por dois meses constataram umidade média em torno de $65 \%$. Esses resultados estão próximos aos valores de umidade $(56,16$ a $64,85 \%)$ obtidos no presente estudo. Nos primeiros 30 dias quase não houve alteração no teor de água das raízes armazenadas sob congelamento, ocorrendo diferenças significativas partir de 60 dias de estocagem, com decréscimo da umidade. Conforme Silva et al. (2002), o mecanismo de troca de vapor de água entre o alimento e o ambiente assume importância no seu processamento, particularmente, durante o armazenamento. De acordo com Hui et al. (2004), o decréscimo observado no teor de umidade deve-se a migração da água do alimento para o ambiente. Esse fenômeno origina-se a partir de temperatura distinta entre o produto e a atmosfera em que foi inserido, resultando em diferença de pressão de vapor que produz fluxo de água da superfície do produto congelado para o ambiente.

Alves et al. (2005), estudando mandiocas minimamente processadas usaram três diferentes embalagens para o e armazenamento sob refrigeração durante 28 dias a $5^{\circ} \mathrm{C}$ : bandeja de isopor envolta em filme de policloreto de vinila; embalagem multicamada de poliéster e polietileno selada sem modificação de atmosfera; e embalagem multicamada de poliéster e polietileno tratada com vácuo (-27 psi). Segundo esses autores, o material da embalagem utilizado para acondicionar as raízes é determinante na dimensão da perda da umidade. Embalagens herméticas, portanto à prova de passagem de água e vapores, devem ser utilizadas para evitar a perda de umidade. Bezerra et 
al. (2002) enfatizaram a importância da manutenção da umidade de raízes de mandioca durante o armazenamento, uma vez que sua diminuição implica em favorecimento das reações enzimáticas que culminam com a descoloração vascular.

TABELA 1 - MÉDIAS DA CARACTERIZAÇÃO FISICO-QUÍMICA DE MANDIOCAS PRÉ-
PROCESSADAS DURANTE PERÍODO DE ARMAZENAMENTO CONGELADO

Tempo de armazenamento (dias)

\begin{tabular}{|c|c|c|c|c|}
\hline Parâmetros & 0 & 7 & 15 & 30 \\
\hline $\begin{array}{c}\text { Umidade } \\
(\%)\end{array}$ & $64,85 \pm 0,11 a$ & $63,86 \pm 0,71 a$ & $63,87 \pm 0,23 a$ & $64,33 \pm 0,25 a$ \\
\hline $\begin{array}{l}\text { Acidez titulável } \\
\text { (\% ác. cítrico) }\end{array}$ & $0,05 \pm 0,00 b$ & $0,05 \pm 0,01 b$ & $0,05 \pm 0,00 b$ & $0,05 \pm 0,00 \mathrm{~b}$ \\
\hline $\mathrm{pH}$ & $6,62 \pm 0,06 a$ & $6,63 \pm 0,04 a$ & $6,62 \pm 0,02 a$ & $6,59 \pm 0,06 a$ \\
\hline \multicolumn{5}{|c|}{ Tempo de armazenamento (dias) } \\
\hline Parâmetros & 60 & 90 & 120 & 150 \\
\hline $\begin{array}{c}\text { Umidade } \\
(\%)\end{array}$ & $58,18 \pm 0,13 b$ & $56,16 \pm 0,38 c$ & $56,71 \pm 0,19 c$ & $57,26 \pm 0,71 b c$ \\
\hline $\begin{array}{l}\text { Acidez titulável } \\
\text { (\% ác. cítrico) }\end{array}$ & $0,05 \pm 0,00 b$ & $0,07 \pm 0,00 a$ & $0,06 \pm 0,00 a$ & $0,07 \pm 0,00 \mathrm{a}$ \\
\hline $\mathrm{pH}$ & $6,61 \pm 0,03 a$ & $6,64 \pm 0,02 a$ & $6,73 \pm 0,06 a$ & $6,61 \pm 0,01^{a}$ \\
\hline
\end{tabular}

Médias seguidas por letras iguais na mesma linha não diferem entre si pelo Teste de Tukey a 5\% de probabilidade.

Para a acidez titulável observa-se, de acordo com a Tabela 1, que não houve diferença significativa para as mandiocas congeladas por até 60 dias de estocagem. Porém, a partir dos 90 dias de armazenamento constatou-se acréscimo significativo de acidez em relação aos períodos anteriores. Segundo Bezerra et al. (2002), o aumento da acidez titulável ocorre devido ao início do processo fermentativo bacteriano com produção de ácidos orgânicos, como o láctico, o butírico e o acético, entre outros.

A variável $\mathrm{pH}$ não apresentou diferença significativa durante o armazenamento das raízes de mandioca, verificando-se pH médio de 6,63 no período de 150 dias. Esse resultado está de acordo com Oliveira, Pantaroto e Cereda (2003) em estudo com toletes de mandioca acondicionados em sacos de polietileno $+\mathrm{EVOH}$ armazenados sob temperatura de $4^{\circ} \mathrm{C}$, por 28 dias, que encontraram valor médio de $\mathrm{pH}$ de 6,89 .

\subsection{AVALIAÇÃO SENSORIAL}

Os resultados verificados na análise sensorial, aplicada durante diferentes dias de armazenamento das raízes de mandioca, estão expressos na Tabela 2.

As mandiocas pré-processadas e armazenadas sob congelamento foram aceitas sensorialmente, durante todo o período avaliado (150 dias), com notas médias variando de 7,40 a 8,39 ("gostei moderadamente" e "gostei muitíssimo"). Para todos os atributos avaliados não foi observada diferença significativa $(p<0,05)$ durante os 150 dias de armazenamento. Isso demonstra que o pré-processamento da mandioca, seguido pelo armazenamento congelado mantém suas características sensoriais próximas às do produto in natura, representando método prático e eficiente para sua conservação por 150 dias. 
TABELA 2 - RESULTADOS DA ANÁLISE SENSORIAL DE MANDIOCA COZIDA EM RELAÇÃO
AO TEMPO DE ARMAZENAMENTO SOB CONGELAMENTO

\begin{tabular}{ccccc}
\hline $\begin{array}{c}\text { Tempo } \\
\text { (dias) }\end{array}$ & Aroma & Cor & Sabor & $\begin{array}{c}\text { Impressão } \\
\text { Global }\end{array}$ \\
\hline 0 & $7,40^{\mathrm{a}}$ & $7,47^{\mathrm{a}}$ & $7,97^{\mathrm{a}}$ & $7,77^{\mathrm{a}}$ \\
7 & $7,77^{\mathrm{a}}$ & $7,90^{\mathrm{a}}$ & $7,87^{\mathrm{a}}$ & $7,63^{\mathrm{a}}$ \\
15 & $7,63^{\mathrm{a}}$ & $7,77^{\mathrm{a}}$ & $7,67^{\mathrm{a}}$ & $7,70^{\mathrm{a}}$ \\
30 & $7,94^{\mathrm{a}}$ & $7,84^{\mathrm{a}}$ & $8,39^{\mathrm{a}}$ & $8,06^{\mathrm{a}}$ \\
60 & $7,74^{\mathrm{a}}$ & $7,35^{\mathrm{a}}$ & $7,68^{\mathrm{a}}$ & $7,68^{\mathrm{a}}$ \\
90 & $8,07^{\mathrm{a}}$ & $7,77^{\mathrm{a}}$ & $8,03^{\mathrm{a}}$ & $7,87^{\mathrm{a}}$ \\
120 & $8,00^{\mathrm{a}}$ & $7,60^{\mathrm{a}}$ & $7,73^{\mathrm{a}}$ & $7,57^{\mathrm{a}}$ \\
150 & $8,10^{\mathrm{a}}$ & $8,03^{\mathrm{a}}$ & $7,87^{\mathrm{a}}$ & $7,87^{\mathrm{a}}$ \\
\hline
\end{tabular}

Letras iguais na mesma coluna indicam que não houve diferença significativa entre as amostras, ao nível de 95\% de confiança $(p<0,05)$.

\section{CONCLUSÃO}

Os resultados da caracterização físico-química e sensorial obtidos neste trabalho sugerem que o congelamento de raízes de mandioca pré-processadas acondicionadas em sacos plásticos constitui método eficaz para retardar o surgimento de modificações e deteriorações, sendo possível prolongar sua vida útil por até 150 dias.

\section{ABSTRACT}

\section{PHYSICO-CHEMICAL AND SENSORY EVALUATION OF CASSAVA PRE-PROCESSED STORED UNDER FREEZING}

The aim of this study was to evaluate the physicochemical and sensory characteristics changes in pre-processed cassava during storage under freezing. The cassava roots were selected, washed in water, peeled and cut manually, cleaned, packed in polyethylene bags and stored at $-18^{\circ} \mathrm{C}$ for 150 days and analyzed after $0,7,15$, 30, 60, 90, 120 and 150 days for $\mathrm{pH}$, acidity, moisture analysis and sensory acceptance. The average moisture value found for cassava roots frozen for 150 days was of $60.65 \%$. The variable $\mathrm{pH}$ of cassava roots was not significantly different during the whole period. However, it was observed a significant increase in the acidity of cassava roots from 90 days of storage. Regarding the sensory analysis, for all attributes evaluated, the observed means for the time zero and time 150 days remained virtually unchanged and close to the concept "liked very much." The results suggest that the freezing of the roots of pre-processed cassava is an efficient method for delaying the onset of changes and deterioration, which can prolong its life by up to 150 days.

KEY-WORDS: Manihot esculenta Crantz; CASSAVA - PRE-PROCESSING; CASSAVA - FREEZING, SENSORY EVALUATION.

\section{REFERÊNCIAS}

1 ALVES, A.; CANSIAN, R. L.; STUART, G.; VALDUGA, E. Alterações na qualidade de raízes de mandioca (Manihot esculenta Crantz) minimamente processadas. Ciência e Agrotecnologia, Lavras, v. 29, n. 2, p. 330-337, mar./abr., 2005.

2 AOAC. Association of Official Analytical Chemists. Official methods of analysis of the AOAC International. $16^{\text {th }}$ ed. Washington, 1997.

3 BERK, Z. Food process engineering and technology. San Diego: Elsevier, 2009. 622 p.

4 BEZERRA, V. S.; PEREIRA, R. G. F. A.; CARVALHO, V. D.; VILELA, E. R. Raízes de mandioca minimamente processadas: efeito do branqueamento na qualidade e na conservação. Ciência e Agrotecnologia, Lavras, v. 26, n. 3, p. 564-575, mai./jul. 2002. 
5 BORGES, M. F.; FUKUDA, W. M. G.; ROSSETTI, A. G. Avaliação de variedades de mandioca para consumo humano. Pesquisa Agropecuária Brasileira, Brasília, v.37, n.11, p. 1559-1565, 2002.

6 BRUNO, L. M.; QUEIROZ, A. A. M.; ANDRADE, A. P. C.; VASCONCELOS, N. M.; BORGES, M. F. Avaliação microbiológica de hortaliças e frutas minimamente processadas comercializadas em fortaleza (CE). Boletim do CEPPA, Curitiba, v. 23, n. 1, p. 17-84, jan./jun. 2005.

7 CENI, G. C.; COLET, R.; PERUZZOLO, M.; WITSCHINSKI, F.; TOMICKI, L.; BARRIQUELLO, A. L.; VALDUGA, E. Avaliação de componentes nutricionais de cultivares de mandioca (Manihot esculenta Crantz). Alimentos e Nutrição, Araraquara, v. 20, n. 1, p. 107-111, jan./mar. 2009.

8 COSTA, M. R; CARDOSO, E. R.; OHAZE, M. M. M. Similaridade genética de cultivares de mandioca (Manihot esculenta) por meio de marcadores RAPD. Ciência e Agrotecnologia, Lavras, v. 27, n. 1, p. 158-164, jan./fev. 2003.

9 FAO. Food and Agricultural Organization. Food outlook: global market analysis - November 2008. Available at: < http:// www.fao.org/docrep/011/ai474e/ai474e06.htm>. Accessed on: Mar. $8^{\text {th }} 2010$.

10 FELLOWS, P. J. Food processing technology: principles and practice. $2^{\text {nd }}$ ed. Cambridge: CRC Press, 2000.606 p.

11 FENNEMA, O. R. Food chemistry. $3^{\text {rd }}$ ed. Wisconsin: Marcel Dekker, 1996. 1262 p.

12 HUI, Y.H.; CONILLON, P.; LEGARETTA, G. I.; LIM, H. M.; MURRELL, K.D.; NIP, W.K. Handbook of frozen foods. New York: Marcel Deker, 2004. 707 p.

13 JAY, J. M. Modern food microbiology. $6^{\text {th }}$ ed. Gaithersburg: Aspen Publishers, 2000. 625 p.

14 OLIVEIRA, M. A.; PANTAROTO, S.; CEREDA, M. P. Efeito da sanitização e de agente antioxidante em raízes de mandioca minimamente processadas. Brazilian Journal of Food Technology, v.6, n.2, p. 339-344, jul./dez. 2003.

15 OLIVEIRA, M.A.; LEONEL, M.; CABELLO C.; CEREDA, M. P.; JANES, D. A. Metodologia para avaliação do tempo de cozimento e características tecnológicas associadas em diferentes cultivares de mandioca. Ciência e Agrotecnologia, Lavras, v. 29, n. 1, p. 126-133, 2005.

16 OLIVEIRA, M. A. Conservação pós-colheita de mandioca de mesa. Disponível em: <http://www.cerat.unesp.br/ compendio/palestras/palestra7.pdf>. Acesso em: 22 fev. 2010.

17 SILVA. M. M.; GOUVEIA, J. P. G.; ALMEIDA, F. A.C.; SILVA, M. M. Demanda energética envolvida no processo de dessorção de umidade em polpa de manga. Revista Brasileira de Produtos Agroindustriais, Campina Grande, v. 4, n. 2, p. 107-117, 2002.

18 STONE, H. S.; SIDEL, J. L. Sensory evaluation practices. $2^{\text {nd }}$ ed. San Diego: Academic Press, 1993.338 p. 